\title{
New Spectrophotometric Methods for Estimation of Perindopril Erbumine in Bulk and Pharmaceutical Formulations
}

\author{
Aziz Unnisia," K. V. Gopala Raju, A. N. Jyothi, and K. Balaji \\ KVSR Siddhartha College of Pharmaceutical Sciences, Vijayawada-520010, AP, India
}

Received 7 August 2013, accepted in final revised form 4 January 2014

\begin{abstract}
Three rapid, simple, inexpensive, precise, and accurate spectrophotometric procedures were developed for the determination of Perindopril erbumine (PPE) using cobalt-thiocyanate, citric acid and 2,3- dichloro-5,6-dicyano benzoquinone in bulk sample and in dosage forms. The procedures are based on the coordination complex of the drug (electron donor) and the chromogenic reagents used. The colored products are extracted into non aqueous solvents and measured spectrophotometrically at the optimum $\lambda_{\max }$ for each complex. Regression analysis of Beer-Lambert plots showed good correlation in the concentration range of 30-70 $\mu \mathrm{g} \mathrm{mL} \mathrm{m}^{-1}, 4-20 \mu \mathrm{g} \mathrm{mL}^{-1}$ and $20-60 \mu \mathrm{g} \mathrm{mL}^{-1}$ for cobalt-thiocyanate, citric acid and 2,3dichloro-5,6-dicyano benzoquinone respectively. The apparent molar absorptivity, Sandell's sensitivity, detection and quantification limits were calculated. The developed methods were successfully applied for the determination of PPE in bulk and pharmaceutical formulations without any interference from common excipients and hence can be used for their routine analysis.
\end{abstract}

Keywords: Perindopril erbumine; Spectrophotometry; Cobalt-thiocyanate; Citricacid-acetic anhydride.

(c) 2014 JSR Publications. ISSN: 2070-0237 (Print); 2070-0245 (Online). All rights reserved.

doi: http://dx.doi.org/10.3329/jsr.v6i2.16106 J. Sci. Res. 6 (2), 319-327 (2014)

\section{Introduction}

Perindopril Erbumine (PPE) chemically [1] is $(2 S, 3 a S, 7 a S)-1-[(2 S)-2-\{[(2 S)-1-$ ethoxy-1oxopentan-2-yl]amino propanoyl]-octahydro- $1 H$-indole-2-carboxylic acid. It [2] is a long-acting ACE inhibitor used to treat high blood pressure, heart failure or stable coronary artery disease. PPE is official in B.P and USP.

Literature survey reveals only few analytical techniques such as HPTLC [3], HPLC [46], GC-MS [7], capillary gas chromatography [8, 9], LC-MS/MS [10, 11], radioimmunoassay [12], amperometry [13], potentiometry [14] and spectrophotometry [15-17] for the quantification of PPE in biological fluids and pharmaceutical dosage forms. However, some of these methods used expensive instrument and costly solvents while the others lacked sensitivity and selectivity. The analytically important functional groups were not fully exploited for the precise and accurate estimation of the drug in bulk

\footnotetext{
*Corresponding author: khushiazeez @yahoo.co.in
} 
and pharmaceutical formulations. Hence the aim of the author was to develop economic, sensitive and specific spectrophotometric methods utilizing various reactions between chromophoric reagents like cobalt-thiocyanate [18], citricacid-acetic anhydride [18] and 2,3- dichloro-5,6-dicyano benzoquinone [19] with analytically important functional groups present in the drug.

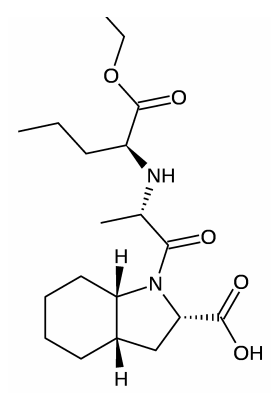

Fig. 1. Structure of perindopril erbumine

\section{Experimental}

\subsection{Instruments used}

A Systronics Double beam UV-Visible spectrophotometer 2201 with $1 \mathrm{~cm}$ matched quartz cells was used for all spectral and absorbance measurements. A Systronics digital pH meter was used for all $\mathrm{pH}$ measurements.

\subsection{Preparation of reagents}

All the chemicals and reagents used were of analytical grade and solutions were prepared using appropriate solvents.

\subsubsection{For method $M_{1}$}

Cobalt thiocynate [CTC solution $\left(2.5 \times 10^{-1} \mathrm{M}\right)$ ] was prepared by dissolving $7.25 \mathrm{~g}$ of cobaltous nitrate $(\mathrm{BDH})$ and $3.8 \mathrm{~g}$ of ammonium thiocynate $(\mathrm{BDH})$ in $100 \mathrm{~mL}$ distilled water. Buffer solution ( $\mathrm{pH} 2.0)$ : Prepared by mixing $306 \mathrm{~mL}$ of trisodium citrate $(0.1 \mathrm{M})$ with $694 \mathrm{~mL}$ of $\mathrm{HCl}(0.1 \mathrm{M})$ and the $\mathrm{pH}$ was adjusted to 2.0. Nitrobenzene (Qualigens) AR grade was used.

\subsubsection{For method $M_{2}$}

Citric acid-acetic anhydride [CA/ $\mathrm{Ac}_{2} \mathrm{O}$ solution (Fluka: $0.2 \% \mathrm{w} / \mathrm{v}, 3.26 \times 10^{-3} \mathrm{M}$ )] [18]: Accurately $12 \mathrm{~g}$ of citric acid monohydrate was weighed and transferred to $250 \mathrm{~mL}$ 
beaker. The beaker was kept in ice water bath. To this beaker $5 \mathrm{~mL}$ of methanol and 20 $\mathrm{mL}$ of acetic anhydride were added. The mixture was stirred with a glass rod to complete the dissolution. The solution was transferred to $100 \mathrm{~mL}$ volumetric flask and final volume adjusted to mark with acetic anhydride.

\subsubsection{For method $M_{3}$}

2,3- Dichloro-5,6-dicyano benzoquinone (DDQ) $\left(8.8 \times 10^{-3} \mathrm{M}\right)$ : Prepared by dissolving $200 \mathrm{mg}$ of DDQ in $100 \mathrm{~mL}$ of Acetonitrile.

\subsection{Preparation of standard drug solution}

\subsubsection{For method M1}

About $119.16 \mathrm{mg}$ of PPE (equivalent to $100 \mathrm{mg}$ of free base) was accurately weighed and transferred to $150 \mathrm{~mL}$ separating funnel. It was dissolved in $10 \mathrm{~mL}$ of water and $10 \mathrm{~mL}$ of $0.1 \mathrm{~N}$ sodium hydroxide was added to it drop wise to release the free base of the drug. The released free base was extracted 3 times with $20 \mathrm{~mL}$ portions of chloroform solvent and volume of the total chloroform extract was brought up to $100 \mathrm{~mL}$ with chloroform to get a standard stock solution of $1 \mathrm{mg} / \mathrm{mL}$.

\subsubsection{For method M2}

The stock solution $(1 \mathrm{mg} / \mathrm{mL})$ of PPE was prepared by dissolving $100 \mathrm{mg}$ of the drug in $100 \mathrm{~mL}$ water. This stock solution was further diluted to get the working standard solution of concentration $100 \mu \mathrm{g} / \mathrm{mL}$.

\subsubsection{For method $M_{3}$}

The stock solution $(1 \mathrm{mg} / \mathrm{mL})$ of PPE was prepared by dissolving $100 \mathrm{mg}$ of the drug in $100 \mathrm{~mL}$ of acetonitrile. This stock solution was used as such for this method.

\subsection{Procedure for estimation}

After systematic and detailed study of the various parameters involved in the optimization of the methods, the following procedures were recommended for the determination of PPE in bulk and pharmaceutical dosage forms.

\subsubsection{For bulk samples}

\subsubsection{Method $M_{1}$}

Into a series of $125 \mathrm{~mL}$ separating funnels, PPE standard solution $(1000 \mu \mathrm{g} / \mathrm{mL})$ ranging from 0.3 to $0.7 \mathrm{~mL}$ was transferred and the volume in all separating funnels was adjusted 
to $2.0 \mathrm{~mL}$ with water. Then $5.0 \mathrm{~mL}$ of buffer $(\mathrm{pH} 2.0)$ and $5.0 \mathrm{~mL}$ of CTC were added. The total volume in each separating funnel was adjusted to $115.0 \mathrm{~mL}$ with distilled water. To each separating funnel $10 \mathrm{~mL}$ of nitrobenzene was added and contents were shaken for 5 min. The two phases were allowed to separate and the absorbance of the separated nitrobenzene layer was measured at $620 \mathrm{~nm}$ against a reagent blank. The amount of PPE was deduced from its Beer-Lambert's plot.

\subsubsection{Method $M_{2}$}

Aliquots of standard chloroformic PPE solutions containing $(0.4-2.0 \mathrm{~mL}$ of $100 \mu \mathrm{g} / \mathrm{mL})$ were transferred to a series of $25 \mathrm{~mL}$ volumetric flasks and gently evaporated on a water bath to remove the chloroform. $10 \mathrm{~mL}$ of $\mathrm{CA} / \mathrm{Ac}_{2} \mathrm{O}$ reagent was added to each volumetric flask. The volumetric flasks were placed in a water bath and heated for $40 \mathrm{~min}$. The contents were cooled to room temperature and the solution in each volumetric flask was made up to the mark with acetic anhydride and set aside for $15 \mathrm{~min}$. The absorbance of colored solutions was measured at $580 \mathrm{~nm}$ against a reagent blank. The amount of PPE in sample was calculated from its calibration graph.

\subsubsection{Method $M_{3}$}

To a series of $10 \mathrm{~mL}$ volumetric flasks, aliquots of standard PPE solutions (free base) containing 200.0 to $600.0 \mu \mathrm{g}$ were transferred and $1.0 \mathrm{~mL}$ of DDQ was added to each volumetric flask. The final volume was made up to the mark with acetonitrile. The absorbance of the solutions was measured at $404 \mathrm{~nm}$ against its reagent blank. The amount of PPE was computed from its Beer-Lambert's plot.

\subsection{For pharmaceutical formulations}

\subsubsection{For method $M_{1}$}

Twenty tablets (Aceon) were taken in a mortar and crushed to a fine powder. From this tablet powder equivalent to $50 \mathrm{mg}$ of PPE was taken and dissolved in $40 \mathrm{~mL}$ of water. The solution was filtered and diluted to $50 \mathrm{~mL}$ with the same solvent. It was further diluted appropriately with the same solvent and amount of PPE was estimated by following the same procedure as described in bulk samples for method $\mathrm{M}_{1}$.

\subsubsection{For method $M_{2}$}

Tablet powder equivalent to $50 \mathrm{mg}$ of PPE was accurately weighed and transferred to 150 $\mathrm{mL}$ separating funnel. Then it was dissolved in $10 \mathrm{~mL}$ of water and $10 \mathrm{~mL}$ of $0.1 \mathrm{~N}$ sodium hydroxide was added to it drop wise to precipitate the free base of the drug. The 
released free base was extracted 2 times with $20 \mathrm{~mL}$ portions of chloroform solvent and volume of the total chloroform extract was brought up to $50 \mathrm{~mL}$ with chloroform to get a standard stock solution of $1 \mathrm{mg} / \mathrm{mL}$ This stock solution was used in determination of PPE in formulations by following the procedure just as described in bulk samples for method $\mathrm{M}_{2}$.

\subsubsection{Method $M_{3}$}

Powder equivalent $50 \mathrm{mg}$ of PPE was taken and sample was extracted into $50 \mathrm{~mL}$ acetonitrile. After performing appropriate dilutions, the amount of PPE in the sample was determined by following the procedure as described in bulk sample for method $\mathrm{M}_{3}$.

\section{Results and Discussions}

\subsection{Method $M_{1}$}

CTC has been proved to be a valuable chromogenic reagent for the detection and determination of pharmaceutical compounds containing tertiary amino compounds and phenothiazines. The colored species formed is the coordination complex of the drug (electron donor) and the central metal atom of CTC, which is extracted into non-aqueous solvents (usually nitrobenzene) from aqueous solution. The green colored complex formed between the reagent and PPE can be attributed to presence of cyclic tertiary nitrogen.

\subsubsection{Reaction for PPE}

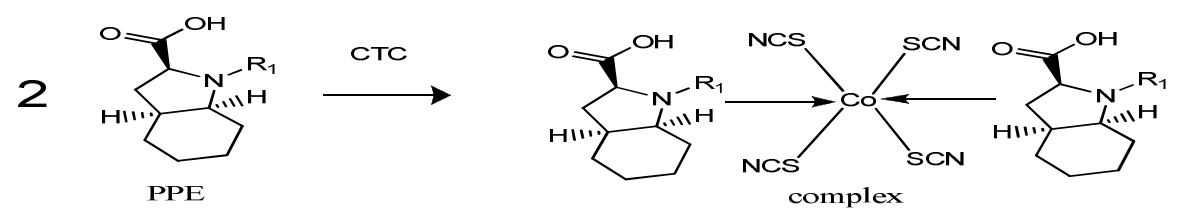

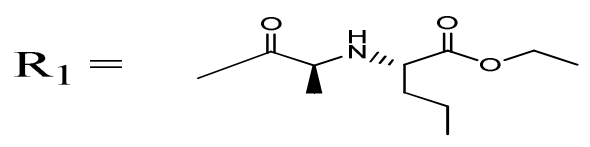

\subsection{Method $\mathrm{M}_{2}$}

Scheme 1

When basic tertiary amines are heated with a solution of citric acid (or cis-aconitic anhydride) in acetic anhydride, a red-violet colored molecular internal salt is formed. The trans-configuration of aconitic acid initially forms through dehydration besides cis- 
aconitic anhydride and subsequently yields $\alpha ; \gamma$-anhydride develops violet color in the presence of tertiary amine which allows the colorimetric determination of class of compounds.

Formation of an internal salt of aconitic anhydride with tertiary nitrogen in PPE is responsible for red-violet color formation. The probable sequence of reactions based on analogy is presented in scheme 1 (PPE).

\subsubsection{Reaction for PPE}<smiles>O=C(O)CC(O)(CC(=O)O)C(=O)O</smiles>

Citric acid

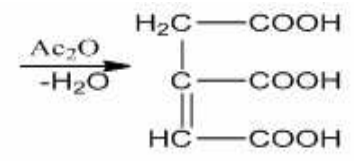

Aconitic acid<smiles>CCCOCCO</smiles>

Aconitic anhydride

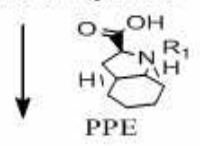

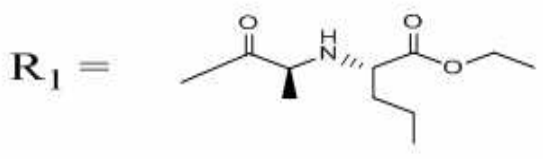

Scheme 2

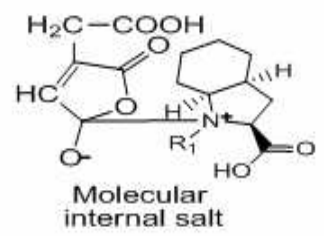

\subsection{Method $\mathrm{M}_{3}$}

Compounds with cyclic tertiary nitrogen of aliphatic nature (like PPE) function as electron donor and participates in charge transfer interaction with substituted quinones (DDQ). The colored species formation appears to be due to formation of radical anion. The formation of a radical anion in such molecular interactions has been established by electron spin resonance measurements. Based on analogy, reaction is given in scheme 3 .

In order to ascertain the optimum wavelength of maximum absorption $\left(\lambda_{\max }\right)$, the spectra were scanned in the wavelength region of 400-800 $\mathrm{nm}$ against a corresponding reagent blank. The reagent blank absorption spectrum of each method was recorded against solvent employed in each method.

Beer's law limits, molar absorptivity, sandell's sensitivity and optimum photometric range for PPE in each method developed with mentioned reagents were calculated. Least square regression analysis was carried out for getting the slope, intercept and correlation coefficient values. These are recorded in Table1. 


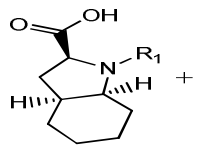

PPE<smiles></smiles>

DDQ

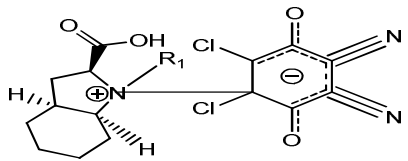

Radical anion<smiles>[R][Tl]=C</smiles>

Scheme 3

Table 1. Optical characteristics, regression data and precision of the proposed methods for PPE.

\begin{tabular}{lccc}
\hline \multicolumn{1}{c}{ Parameter } & $\mathrm{M}_{1}$ & $\mathrm{M}_{2}$ & $\mathrm{M}_{3}$ \\
\hline$\lambda_{\text {max }}(\mathrm{nm})$ & 620 & 580 & 404 \\
Beer's law limits $(\mu \mathrm{gmL})$ & $30-70$ & $4-20$ & $20-60$ \\
Molar absorptivity $\left(\mathrm{L} \mathrm{mole}{ }^{-1} \mathrm{~cm}^{-1}\right)$ & $2.9 \times 10^{3}$ & $1.3 \times 10^{4}$ & $4.5 \times 10^{3}$ \\
Limit of detection $(\mu \mathrm{g} / \mathrm{mL})$ & 0.0971 & 0.0206 & 0.5099 \\
Sandell's sensitivity & & & \\
$\left(\mu \mathrm{g} / \mathrm{cm}^{2} / 0.001\right.$ absorbance unit) & 0.1260 & 0.0347 & 0.0980 \\
Regression equation: slope $(b)$ & 0.0079 & 0.0298 & 0.0100 \\
Standard deviation of slope $(\mathrm{Sb})$ & $4.95 \times 10^{-6}$ & $1.5 \times 10^{-4}$ & $4.4 \times 10^{-4}$ \\
Intercept (a) & $2.703 \mathrm{E}-0.5$ & 0.0003 & 0.0004 \\
Standard deviation of intercept $(\mathrm{Sa})$ & $2.7 \times 10^{-3}$ & $1.8 \times 10^{-3}$ & $1.7 \times 10^{-3}$ \\
Correlation coefficient $(r)$ & 0.9999 & 0.9998 & 0.9999 \\
\% Relative standard deviation* & 0.2173 & 0.1709 & 0.279 \\
$\%$ Error in bulk samples** & 0.0970 & 0.0975 & 0.1222 \\
& & & \\
\hline
\end{tabular}

* Average of six determinations ; ** Average of three determinations.

Interference studies were conducted to see the influence of excipients with the proposed methods. The accuracy of the methods was evaluated by estimating the amount of PPE in previously analyzed samples to which known amounts of PPE was spiked. The accuracy of the methods was also confirmed by comparison of the results obtained by proposed and reference methods. The results of accuracy were given in Table 2. Some of the commercially available formulations were procured from the local market and analyzed by the developed methods and the results comply with the labeled claim. 
Table 2. Assays and recovery of PPE in dosage forms [20, 21].

\begin{tabular}{|c|c|c|c|c|c|c|c|}
\hline \multirow[t]{2}{*}{ Method } & \multirow{2}{*}{$\begin{array}{l}\text { Pharma- } \\
\text { ceutical } \\
\text { formulation }\end{array}$} & \multirow{2}{*}{$\begin{array}{c}\text { Labeled } \\
\text { amount } \\
\text { (mg) }\end{array}$} & \multicolumn{3}{|c|}{ Proposed method } & \multirow{2}{*}{$\begin{array}{l}\text { Found by } \\
\text { reference } \\
\text { method }\end{array}$} & \multirow{2}{*}{$\begin{array}{c}\% \text { Recovery } \\
\text { by proposed } \\
\text { methods** }\end{array}$} \\
\hline & & & $\begin{array}{c}\text { Amount } \\
\text { found* }(\mathrm{mg})\end{array}$ & $\begin{array}{c}t \\
\text { (value) }\end{array}$ & $\begin{array}{c}F \\
\text { (value) }\end{array}$ & & \\
\hline $\mathrm{M}_{1}$ & Tablet-I & 8 & $7.91 \pm 0.019$ & 0.892 & 2.026 & $7.94 \pm 0.006$ & $99.64 \pm 0.52$ \\
\hline $\mathrm{M}_{2}$ & Tablet-I & 8 & $8.01 \pm 0.009$ & 0.658 & 2.439 & $8.01 \pm 0.091$ & $99.92 \pm 1.08$ \\
\hline $\mathrm{M}_{3}$ & Tablet-I & 8 & $7.89 \pm 0.011$ & 0.926 & 2.401 & $8.01 \pm 0.012$ & $99.88 \pm 1.08$ \\
\hline
\end{tabular}

*Average \pm standard deviation of six determinations, the $t$ and $F$-values refer to comparison of the proposed method with reference method. Theoretical values at $95 \%$ confidence limits $t=2.571$ and $F=5.05$.

** Average of five determinations.

\section{Conclusion}

The proposed method is simple, rapid and accurate and can be opted in routine analysis of drug formulation. The accuracy and reproducibility of the method was statistically validated by recovery studies. The proposed method was found to be superior to some of the reported spectrophotometric methods with respect to simplicity, selectivity, linear dynamic range of applicability and cost effectiveness.

\section{References}

1. J. P Bounhoure, G .Bottineau, and P. Lechat, Clin Exp Hypertens. A 11 (suppl 2), 575 (1989).

2. British Pharmacopoeia, London, I, 4612 (2009).

3. V. K Bahl, M. Jadhav, and H. P Thacker, Am. J. Cardiovas. Drugs 9135 (2009).

4. G. D. Mohit, G. B Kailash, and C. D Mrinalini, Int. Res. J. Pharm. 1, 428 (2010).

5. M. Medenica, D. Ivanović, M. Masković, B. Jancić, and A. Malenović, J. Pharm. Anal. 44, 1087 (2007).

6. J. Prajapati, A. Patel, M. B. Patel, N. P. Rashmika, Int. J. Pharm Tech. Res. 3 (2), 801 (2011).

7. A. B. Chaudhary, R. K. Patel, and S.A. Chaudhary, Int. J. Chem. Tech. Res. 2, 1141 (2010).

8. S. Hillaert and W. V. Bossche, J. Chromatogr. A 33, 895 (2000).

9. S. J. Lin, H. L Wu, S. H Chen, and Y. H Wen, Anal. Lett. 29, 1751 (1996). http://dx.doi.org/10.1080/00032719608001521

10. S. J. Deepak, G. Subbaiah, and P. Shrivastav, J. Chromatogr. B 837, 92 (2006). http://dx.doi.org/10.1016/j.jchromb.2006.04.008

11. R. V. Nirogi, V. N. Kandikere, and P. Komarneni, Rapid Commun. Mass Spectrom. 20, 1864 (2006). http://dx.doi.org/10.1002/rcm.2529

12. H. V. Berg and C. J. M. Arts, J. Pharm. Biomed. Anal. 9, 517 (1991). http://dx.doi.org/10.1016/0731-7085(91)80172-6

13. R. I. Stefan, J. F. V. Staden, and H. Y. Aboul-Enein, Sens. Actuators B 54, 261 (1999). http://dx.doi.org/10.1016/S0925-4005(99)00114-8

14. J. F. V. Staden, R. -I. Stefan, and H. Y. Aboul-Enein, Fresennius J. Anal. Chem. 367, 178 (2000). http://dx.doi.org/10.1007/s002160051620

15. S. Sharma and M.C. Sharma, Am.-Eurasian J. Sci. Res. 6 (4), 210 (2011).

16. N. Rahman, H. Rahman, and A.Khatoon, J. Chil. Chem. Soc. 57(2), 1069 (2012). http://dx.doi.org/10.4067/S0717-97072012000200002

17. R. Mukesh, P. Pradeep, and J. Sachin, Am. J. Phytomed. Clinical Therapeutics 1, 78 (2013).

18. K. R. Babu, L. S. Swarup, and B. Kalyanaramu, E- J. Chem. 9 (3), 1645 (2012). 
19. C. Kenneth, P. O. Ukoha, and A. A. Attama, Am. J. Anal. Chem. 2, 849 (2011). http://dx.doi.org/10.4236/ajac.2011.27097

20. Guide for use of terms in reporting data, Anal. Chem. 54, 157(1982)

21. ICH Harmonised Tripartite Guidelines-Q2(R1). 9-10 (2005). 